\title{
Influence of viral infection on the relationships between airway cytokines and lung function in asthmatic children
}

Toby C. Lewis ${ }^{1,4,6}$, Ediri E. Metitiri', Graciela B. Mentz ${ }^{6}$, Xiaodan Ren ${ }^{4}$, Ashley R. Carpenter ${ }^{1}$, Adam M. Goldsmith', Kyra E. Wicklund ${ }^{1,5}$, Breanna N. Eder ${ }^{1}$, Adam T. Comstock', Jeannette M. Ricci', Sean R. Brennan ${ }^{1}$, Ginger L. Washington ${ }^{1}$, Kendall B. Owens ${ }^{1}$, Bhramar Mukherjee ${ }^{3}$, Thomas G. Robins ${ }^{4}$, Stuart A. Batterman ${ }^{4}$, Marc B. Hershenson ${ }^{1,2^{*}}$ and the Community Action Against Asthma Steering Committee

\begin{abstract}
Background: Few longitudinal studies examine inflammation and lung function in asthma. We sought to determine the cytokines that reduce aiflow, and the influence of respiratory viral infections on these relationships.

Methods: Children underwent home collections of nasal lavage during scheduled surveillance periods and selfreported respiratory illnesses. We studied 53 children for one year, analyzing 392 surveillance samples and 203 samples from 85 respiratory illnesses. Generalized estimated equations were used to evaluate associations between nasal lavage biomarkers (7 mRNAs, 10 proteins), lung function and viral infection.

Results: As anticipated, viral infection was associated with increased cytokines and reduced FVC and FEV . However, we found frequent and strong interactions between biomarkers and virus on lung function. For example, in the absence of viral infection, CXCL10 mRNA, MDA5 mRNA, CXCL10, IL-4, IL-13, CCL4, CCL5, CCL20 and CCL24 were negatively associated with FVC. In contrast, during infection, the opposite relationship was frequently found, with IL-4, IL-13, CCL5, CCL20 and CCL24 levels associated with less severe reductions in both FVC and FEV

Conclusions: In asthmatic children, airflow obstruction is driven by specific pro-inflammatory cytokines. In the absence of viral infection, higher cytokine levels are associated with decreasing lung function. However, with infection, there is a reversal in this relationship, with cytokine abundance associated with reduced lung function decline. While nasal samples may not reflect lower airway responses, these data suggest that some aspects of the inflammatory response may be protective against viral infection. This study may have ramifications for the treatment of viral-induced asthma exacerbations.
\end{abstract}

Keywords: Asthma, Chemokine, Children, Cytokine, FEV 1 , FVC, Rhinovirus, Urban, Viral

\section{Background}

Geographic areas with high concentrations of low-income and minority ethnicity residents have high levels of asthma morbidity and mortality [1-3]. The factors leading to loss of asthma control and asthma exacerbations are complex.

\footnotetext{
* Correspondence: mhershen@umich.edu

'Departments of Pediatrics and Communicable Diseases, University of Michigan Medical School, 1150 W. Medical Center Dr., Building MSRB2, Room 3570B, Ann Arbor, Ml 48109-5688, USA

${ }^{2}$ Molecular and Integrative Physiology, University of Michigan Medical School, Ann Arbor, USA

Full list of author information is available at the end of the article
}

Previous studies have identified atopy, inadequate treatment, respiratory viral infections and environmental exposures as important drivers of asthma morbidity [4-7].

The effects of real-world respiratory viral infections on airway inflammation remain largely undefined. We [8] and others [9-12] have examined the innate immune response of children with asthma to natural colds. We found that nasal aspirate cytokine levels significantly increased in children with asthma. In addition, we found that a subset of cytokines (IFN-y, CXCL8, CCL2, CCL4, CCL5, and CCL20) correlated 
with self-reported respiratory tract symptoms. However, we did not examine the influences of viral infection or nasal cytokines on airway function. Further, by limiting comparisons to samples taken during virus-negative well periods and viral-induced exacerbations, we ignored the potential effects of subacute viral infection. Finally, our cross-sectional study did not allow us to examine patterns of variables over time, which could provide more consistent information about the cytokines that drive lung function changes in chronic asthma.

The current study is drawn from an observational cohort of asthmatic school age children from Detroit who were concurrently enrolled in investigations examining the relationship between near-roadway exposures on asthma outcomes [13]. In addition to collecting measures of asthma health, we collected nasal lavage for detection of viral infection and measurement of respiratory tract cytokines and other biomarkers, and performed spirometry to assess lung function. We sought to determine the cytokines that drive reduced airflow, together with the influence of viral infections on these relationships. We hypothesized that children with greater respiratory tract inflammation would demonstrate worse airway function, and that viral infections would increase inflammation and negatively impact asthma symptoms and airway function. While our hypothesis was generally correct, we found that, in the presence of viral infection, higher levels of cytokines were associated with reduced lung function decline.

\section{Methods}

\section{Study design and screening questionnaire}

This study was conducted by Community Action Against Asthma (CAAA), a community-based participatory research (CBPR) partnership. School-age children with known or probable asthma were recruited using a screening questionnaire [14] distributed at community venues and through door-to-door recruitment in neighborhoods near highways. The questionnaire included demographic information, eight symptom questions, and if their child had ever been diagnosed by a medical care provider with any of the following conditions: asthma, bronchitis, bronchiolitis, reactive airways disease, pneumonia, or asthmatic bronchitis. In addition, parents were asked whether their child had taken prescription medication for any of these conditions in the last 12 months and, if so, whether they were taking these medications on a daily basis. Classification of asthma severity was based on symptom frequency and reported inhaled steroid use (Additional file 1: Table S1). This study was approved by the University of Michigan Medical School Institutional Review Board (IRBMED) (ID\# HUM00018442) and conducted according to CBPR principles under the auspices of the CAAA Steering Committee.

\section{Data and sample collection}

Fifty-three children participated in a two-week surveillance assessment period of health status each season from fall 2010 to summer 2011. During each two-week surveillance period, staff obtained spirometry, symptom reports and nasal lavage samples during three home visits. Respiratory symptoms were assessed using a modification of a previously developed respiratory symptom score [15] which assessed fever, cough, sore throat, nasal symptoms, wheezing, difficulty breathing and interference with usual activities (see Additional file 1: Table S2). Families were given a calendar and a simple respiratory symptom scale to mark the level of their symptoms.

From winter 2010 to summer 2011, measurements were repeated during a one-week period whenever the child experienced a symptomatic respiratory illness as defined by a symptom score of two or higher (referred to as a "sick period"). We intentionally set a low symptom threshold in order to maximize sensitivity to detect viral illnesses. Families contacted a central phone number when the child became ill. Staff would tally the symptom score over the phone and when symptoms reached the appropriate threshold, would begin a "sick period" assessment within $48 \mathrm{~h}$ of the phone call (median time to first sample was $72 \mathrm{~h}$ after the development of symptoms). Staff also conducted weekly telephone calls to identify illnesses in progress that families may not have called in to report, and would initiate a "sick period" collection if family reported that the child had current symptoms.

\section{Spirometry}

Using protocols that we developed and successfully utilized in large-scale community-based asthma studies [7], staff conducted spirometry to assess lung function during home visits, using the EasyOne spirometer (NDD, Andover, MA). Additional details on spirometric procedures are described in Additional file 1.

\section{Nasal lavage}

Nasal lavage samples were collected three times during a two-week surveillance period or three times during a one-week sick period by the field staff. Two squirts of isotonic $0.65 \%$ sodium chloride (estimated to be $<1 \mathrm{ml}$ per nostril, B.F. Ascher, Lenexa, KS) were instilled into the child's nostrils Subjects then blew their nose into a zippered plastic bag, and three $\mathrm{ml}$ of M4RT viral transport medium (Remel, Lenexa, KS) was added. After collection, samples were double bagged, placed in a transport cooler at $0{ }^{\circ} \mathrm{C}$, conveyed to a local laboratory (Henry Ford Health System Epidemiology Lab) for preliminary processing and freezing to $-70{ }^{\circ} \mathrm{C}$, and subsequently transported to Ann Arbor on dry ice. 


\section{Detection of respiratory viruses}

Whole nasal lavage samples were homogenized using a hand held homogenizer (Thermo Fisher Scientific, Waltham, MA). Nucleic acids were extracted using TRIzol-LS (ThermoFisher, Waltham, MA), chloroform and an RNeasy Mini Kit (Qiagen, Valencia, CA). Samples were analyzed for viral nucleic acid by multiplex PCR using the Seeplex RV-15 ACE detection kit (Seegene, Concord, CA). This kit detects human adenovirus, bocavirus 1-4, coronaviruses 229E/NL63 and OC43, enterovirus, influenza A and B, metapneumovirus, parainfluenza viruses 1-4, RSV A and B and rhinovirus A, B and C. For surveillance samples, all specimens were analyzed for virus; for sick samples, specimens from the same sick week were pooled prior to analysis (samples from sick periods were not pooled for cytokine or viral copy number determination, see below).

\section{Nasal lavage mRNA and protein expression}

All nasal lavage samples were analyzed for mRNA and protein. cDNA was synthesized from total RNA by Taqman reverse transcriptase kit (Qiagen). DNA was digested with DNase I (Qiagen). CXCL8, CXCL10, IRF7, RIG-I, MDA5, TLR3 and IFN- $\lambda 1$ mRNA expression were measured by qPCR. Specific primers and probes spanning exon-exon junctions (intron splice-sites) were used to prevent amplification of genomic DNA (Additional file 1: Table S3, Online Repository). Expression levels were normalized to GAPDH using the $\Delta \Delta \mathrm{Ct}$ method. Reactions with a cycle number higher than 35 were not included in the analysis. CXCL8, CXCL10, CCL2, CCL4, CCL5, CCL20, CCL24, IL-4, IL-13 and soluble ICAM-1 (sICAM) protein levels were determined by multiplex immune assay (Affymetrix, Santa Clara, CA). Minimum detection levels for the proteins assayed are provided in the Additional file 1: Table S4. Biomarkers were chosen based on previous studies showing elevations after RV infection, our interest in examining biomarkers we had not previously studied, difficulty of detecting some biomarkers or cytokines in the nasal aspirate fluid, cost and availability.

\section{Statistical analysis}

Assessment of the distribution of spirometric data and nasal lavage biomarkers was conducted using means, medians, histograms and QQ plots (data not shown). Because of strong right skewedness, biomarker values were natural $\log$ transformed for subsequent analyses. The effects of viral infection on group median nasal lavage mRNA and protein expression were analyzed by the Wilcoxon $\mathrm{Me}-$ dian Test. We chose to use a non-parametric test because the transformed cytokine distributions were still slightly skewed, with a number of zero values and high outliers which we did not exclude from the analysis. In addition, because we divided subjects and samples by asthma severity, we had a small sample size for some measures. Finally, in the case of TLR3 and IFN- $\lambda 1$ mRNAs, which were detected in only 35 and $11 \%$ of the samples, data were analyzed as binary variables by Fisher's exact test.

For our primary analyses, we evaluated the strength of association between mean respiratory tract inflammatory responses and pulmonary function using generalized estimating equations (GEE) with an exchangeable correlation structure using the identity link in the case of continuous outcomes and the log link for binary ones (SAS, Cary, $\mathrm{NC}$ ). This design allowed us to test the influence of cytokine on lung function with and without virus. GEE was used rather than logistic or Poisson models because of the longitudinal nature of the data and the repeated observations for each child $[16,17]$. The GEE procedure can be used for small populations [18]. All individual samples (virus-negative and virus-positive "surveillance samples," virus-negative and virus-positive "sick samples") were included in the analysis. We adjusted for covariates including age, gender, ethnicity/ race, smoker in the home, caregiver educational attainment, self-reported atopy, caregiver depressive symptom score, season and whether the sample was from a surveillance or sick period. Family income, baseline asthma severity, medication use and proximity to high-traffic highways were evaluated but not included in final models as they were not significant predictors or were collinear with other covariates in the model. In a secondary analysis, linear plots of lung function and cytokine level when virus was either absent or present were generated. Additional details on statistical analysis are described in Additional file 1.

\section{Results}

\section{Study participants}

Fifty-three children between 5 and 12 years-old were enrolled. Subjects predominantly self-identified as African-American (Table 1). The majority was reported by their parent/caregiver to be atopic, exposed to tobacco smoke and live in a household with an income s $\$ 15,000$. Most children reported symptoms or medication use consistent with mild intermittent or mild persistent asthma, but one-quarter had moderate-to-severe persistent disease. At enrollment, one-quarter of the subjects were taking inhaled corticosteroids or used them within the last year. Group mean FVC, $\mathrm{FEV}_{1}$ and PEF during the first surveillance period were in the range of normal, but $\mathrm{FEV}_{1} / \mathrm{FVC}$ ratio and $\mathrm{FEF}_{25-75}$ were reduced (Table 2). It should be noted that, although all children met initial criteria for participation, only 47 of 53 children performed acceptable expiratory maneuvers for spirometric analysis.

\section{Participant respiratory illnesses}

From September 2010 to August 2011, 392 surveillance samples were collected, 105 (26\%) of which were positive 
Table 1 Participant baseline characteristics $(n=53)$

Age in years, mean (SD)
Female gender, $\mathrm{n}(\%)$
Race, Non-Hispanic African-American, $\mathrm{n}(\%)$
Household income $\leq \$ 15,000, \mathrm{n}(\%)$
Caregiver years of education $\leq 12, \mathrm{n}(\%)$
Caregiver depression CESD score, mean (SD)
Smoker in household, $\mathrm{n}(\%)$
Asthma severity, $\mathrm{N}(\%)$
Moderate or severe persistent
Mild persistent
Mild intermittent
Atopy (self-reported), yes (\%)
Any asthma medication use in last 12 months, $\mathrm{n}(\%)$
Inhaled corticosteroids
Short acting bronchodilator only
No asthma medication
Asthma control test (ACT) score, mean (SD)

for one or more viruses. From December 2010 to August 2011, there were 85 self-reported respiratory illnesses, for which 233 samples were collected. Analysis of pooled samples for each illness showed that 30 (35\%) of these illnesses were positive for at least one virus. RV was detected in 54 out of 105 (51\%) of the virus-positive surveillance samples and 23 out of 30 (77\%) of virus-positive sick illnesses (Table 3).

\section{Effects of viral infection on lung function}

We examined the influence of asthma severity on the lung function response to viral infection. When we divided subjects into mild intermittent, mild persistent and moderate-to-severe persistent asthma, we found that subjects with moderate-to-severe persistent asthma experienced significant $(p<0.05)$ reductions in $\mathrm{FVC}$ and $\mathrm{FEV}_{1}$ after viral infection (Fig. 1). Changes in $\mathrm{FEV}_{1} / \mathrm{FVC}(p=0.08)$ and $\mathrm{FEF}_{25-75}(p=0.09)$ did not reach statistical significance.

Table 2 Baseline surveillance valid health measures

\begin{tabular}{lll}
\hline \multicolumn{1}{l}{ Symptom Score } & $N$ & Median (Range) \\
Lung function (\% of predicted) & 53 & $2.3(0,27)$ \\
FVC & $N$ & Mean (SD) \\
FEV 1 & 43 & $98.5(17.0)$ \\
FEV $_{1} /$ FVC ratio & 43 & $90.3(18.3)$ \\
FEF $_{25-75}$ & 43 & $79.3(6.6)$ \\
PEF & 42 & $70.8(21.9)$ \\
\hline
\end{tabular}

Table 3 Participant viral infections

\begin{tabular}{|c|c|c|}
\hline & $\mathrm{N}$ & $\%$ of total \\
\hline \multicolumn{3}{|c|}{ Surveillance collection $(N=410)$} \\
\hline No virus & 288 & 70.2 \\
\hline Virus & 94 & 22.9 \\
\hline \multicolumn{3}{|l|}{ Rhinovirus } \\
\hline Single infections & 46 & 11.2 \\
\hline Multiple infections & 4 & 1.0 \\
\hline \multicolumn{3}{|l|}{ Non-rhinovirus } \\
\hline Single infections ${ }^{a}$ & 39 & 9.5 \\
\hline Multiple infections & 5 & 1.2 \\
\hline \multicolumn{3}{|c|}{ Cold collection (number of pooled samples $=92$ ) } \\
\hline No virus & 55 & 60.0 \\
\hline Virus & 28 & 30.4 \\
\hline \multicolumn{3}{|l|}{ Rhinovirus } \\
\hline Single infections & 20 & 21.7 \\
\hline Multiple infections & 2 & 2.2 \\
\hline \multicolumn{3}{|l|}{ Non-rhinovirus } \\
\hline Single infections ${ }^{\mathrm{b}}$ & 6 & 6.5 \\
\hline Multiple infections & 0 & 0.0 \\
\hline
\end{tabular}

a Coronavirus 229E/NL63 (9), RSV A (8), coronavirus OC43 (5), RSV B (4), influenza $A$ (4), influenza B (3), adenovirus (2), metapneumovirus (2), parainfluenza 2 (2) ${ }^{b}$ Influenza A (2), influenza B, coronavirus 229E/NL63, parainfluenza 2, RSV B

\section{Effects of viral infection on nasal lavage biomarkers}

All nasal samples were analyzed for mRNA expression of CXCL8, CXCL10, IFN- $\lambda 1$, TLR3, MDA5, RIG-I and IRF7. Samples were also analyzed for CXCL8, CXCL10, IL-4, IL-13, sICAM-1, CCL2, CCL4, CCL5, CCL20 and CCL24 protein. The median individual surveillance and sick period samples analyzed per subject was 7 (range, 1-12) and 3 (range, 2-15), respectively. MDA-5, RIG-I, IRF7, CXCL10 and CXCL8 mRNA were detected in the $73-99 \%$ of the samples, whereas TLR3 and IFN- $\lambda 1$ mRNA were detected in 35 and $11 \%$ of the samples, respectively.

The effect of viral infection on group median cytokine data are shown in Table 4. Viral infections were associated with significantly increased mRNA expression of CXCL10, RIG-I and MDA5 and protein expression of all biomarkers tested. In addition, viral infections were associated with an increase in the percentage of samples with detectable TLR3 and IFN- $\lambda 1$ mRNA. Responses to RV and non-RV infections were generally similar, except for TLR3 mRNA and CXCL8 protein, which were not increased in non-RV infections (data not shown).

Next, we examined the influence of asthma severity on the cytokine responses to viral infection. In subjects with moderate-to-severe persistent asthma, viral infection was associated with significant increases in mRNA expression of CXCL10 and MDA5 (Fig. 2). Viral infection was also associated with increased mRNA expression of CXCL10 in 


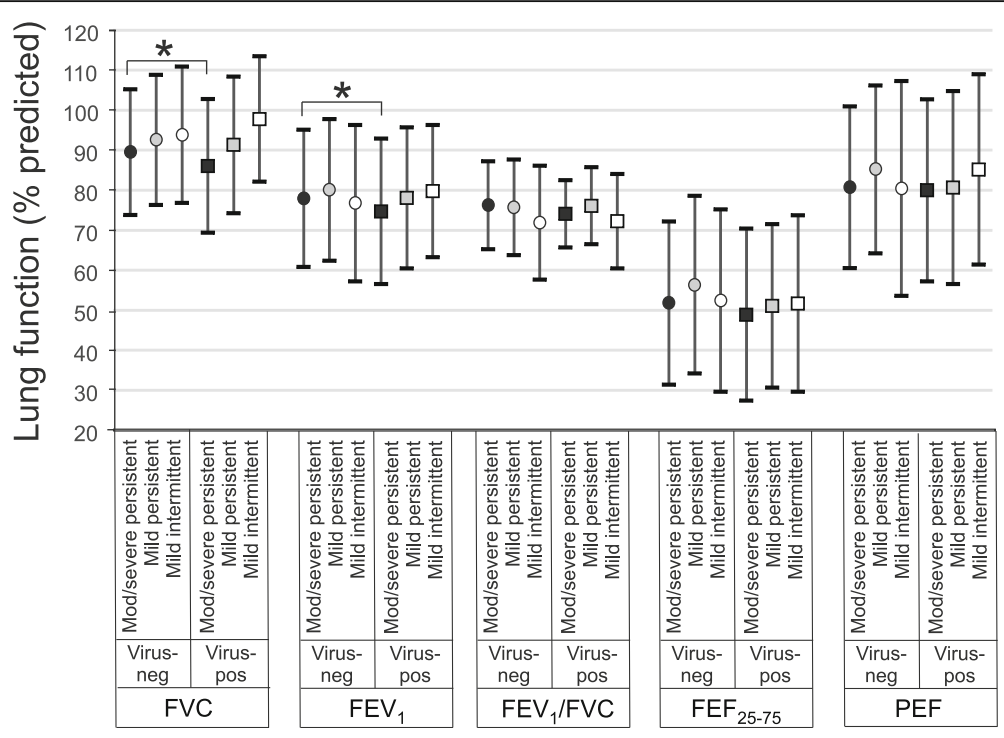

Fig. 1 Effect of viral infection on spirometry in subjects with moderate-to-severe persistent (black symbols), mild persistent (grey symbols) and mild intermittent asthma (white symbols). FVC, FEV1, FEF25-75 and PEF are shown (mean \pm SD). GEE models were used for pairwise comparison of the means $\left({ }^{*} p<0.05\right)$

Table 4 Effect of viral infection on nasal lavage mRNA and protein expression

\begin{tabular}{|c|c|c|c|c|c|c|c|}
\hline \multirow[b]{2}{*}{ mRNA } & \multicolumn{3}{|c|}{ Virus-negative } & \multicolumn{4}{|c|}{ Virus-positive } \\
\hline & $\mathrm{N}$ & Median & IQR & $\mathrm{N}$ & Median & IQR & $p$-value \\
\hline CXCL8 & 404 & 4.68 & $(2.15,9.71)$ & 174 & 5.01 & $(2.45,10.78)$ & 0.54 \\
\hline CXCL10 & 404 & 0.001 & $(0.00,0.01)$ & 174 & 0.0098 & $(0.001,0.06)$ & $<0.01$ \\
\hline IRF7 & 404 & 0.06 & $(0.02,0.14)$ & 174 & 0.06 & $(0.02,0.14)$ & 0.99 \\
\hline RIG-I & 404 & 0.01 & $(0.00,0.03)$ & 174 & 0.02 & $(0.00,0.05)$ & 0.04 \\
\hline MDA5 & 404 & 0.01 & $(0.00,0.03)$ & 174 & 0.02 & $(0.01,0.07)$ & $<0.01$ \\
\hline Binary & N & Detected (\%) & & $N$ & Detected (\%) & & p-value \\
\hline TLR3 & 404 & 132/404 (32.7) & & 174 & $69(39.7)$ & & 0.11 \\
\hline$|F N-\lambda|$ & 404 & 30/404 (7.4) & & 174 & $33(19.0)$ & & $<0.01$ \\
\hline Protein & $N$ & Median & IQR & $N$ & Median & IQR & p-value \\
\hline CXCL8 & 433 & 177.00 & $(71.5,431.6)$ & 172 & 253.35 & $(97.25,868.9)$ & $<0.01$ \\
\hline CXCL10 & 429 & 397.90 & $(213.9,656.2)$ & 171 & 703.20 & $(419.5,1553.5)$ & $<0.01$ \\
\hline IL-4 & 436 & 15.60 & $(4.9,51.65)$ & 175 & 31.10 & $(9.3,75.2)$ & $<0.01$ \\
\hline IL-13 & 428 & 4.60 & $(0.0,27.1)$ & 167 & 18.80 & $(0.0,37.8)$ & $<0.01$ \\
\hline slCAM1 & 431 & 293.20 & $(100.8,643.6)$ & 170 & 560.20 & $(207.6,1219.2)$ & $<0.01$ \\
\hline CCL2 & 433 & 71.40 & $(26.9,132.9)$ & 170 & 103.70 & $(40.3,219.6)$ & $<0.01$ \\
\hline CCL4 & 426 & 300.9 & $(40.3,1261.9)$ & 170 & 1198.65 & $(163.0,3050.6)$ & $<0.01$ \\
\hline CCL5 & 433 & 5.00 & $(0.0,18.1)$ & 174 & 9.55 & $(0.0,27.4)$ & $<0.01$ \\
\hline CCL20 & 439 & 290.3 & $(78.0,651.1)$ & 178 & 580.0 & $(186.1,1184.5)$ & $<0.01$ \\
\hline CCL24 & 434 & 4.47 & $(1.06,14.24)$ & 175 & 9.16 & $(2.56,21.06)$ & $<0.01$ \\
\hline
\end{tabular}

Levels of mRNA expression are normalized to GAPDH. Group median data are shown except for TLR3 and IFN- $\lambda 1$ mRNA, for which results were analyzed as binary variables. Samples were divided into virus-negative and virus positive. Differences were analyzed by the Wilcoxon Median Test except for TLR3 and IFN- $\lambda 1$ which were analyzed by Fisher's exact test 

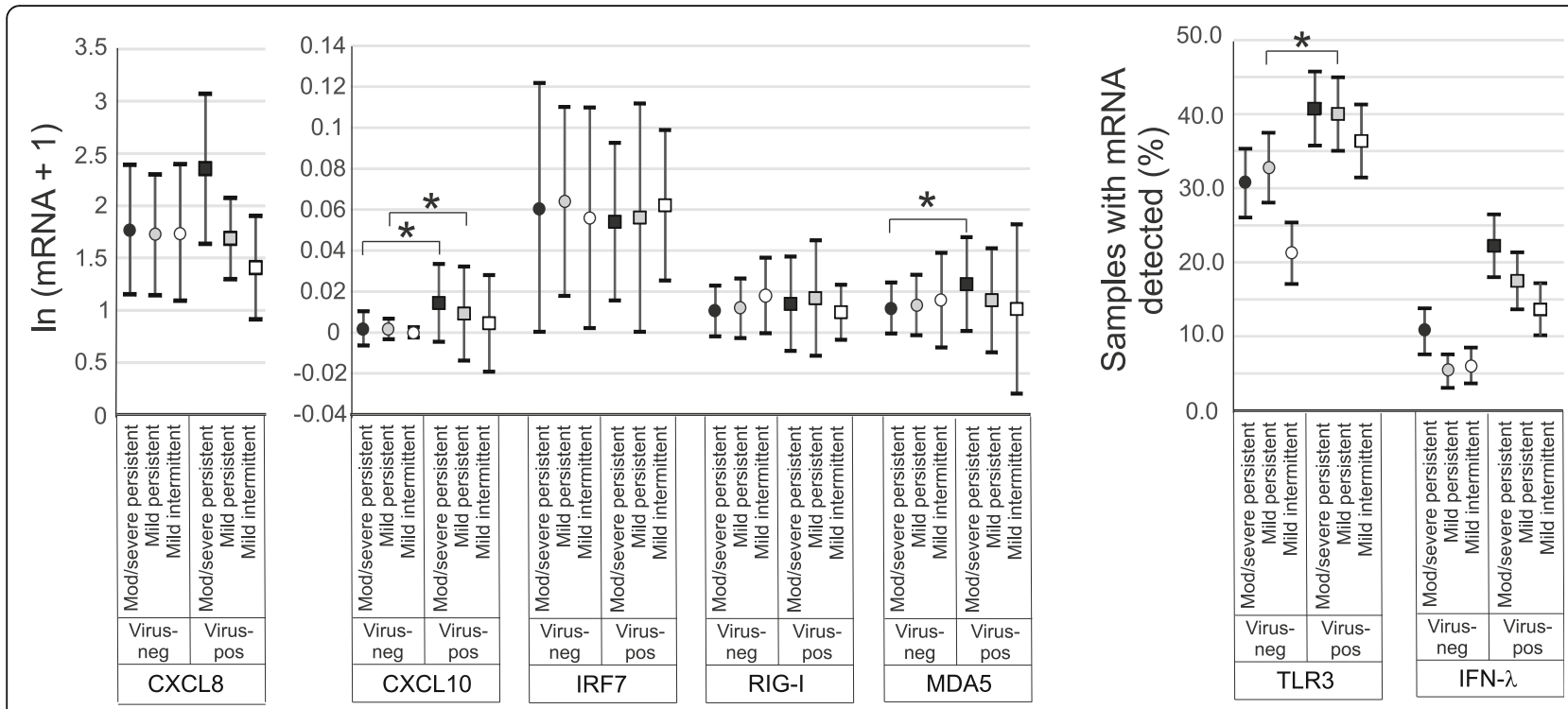

Fig. 2 Effect of viral infection on nasal lavage mRNAs by asthma severity. mRNA expression was measured by qPCR and normalized by GAPDH. Medians \pm IQR are shown. TLR3 and IFN- $\lambda 1$ mRNA results were analyzed as binary variables (proportions and 95\% confidence intervals are shown. Pairwise comparisons of medians were performed using the Wilcoxon Rank-Sum Test (red squares, moderate-to-severe persistent asthma; blue squares, mild persistent asthma; green squares, mild intermittent asthma; ${ }^{*} p<0.05,+0.05<p<0.10$ )

subjects with mild persistent asthma. Viral infection was associated with an increase in the number of samples with detectable TLR3 mRNA expression in subjects with mild persistent asthma. Finally, compared to other virus-positive groups, the number of IFN- $\lambda 1$ mRNA-positive samples tended to be higher in infected subjects with moderate-to-severe asthma $(p=0.09)$.

In moderate-to-severe persistent asthmatics, viral infection was associated with increased protein abundance of CXCL10, IL-4, sICAM-1, CCL2, CCL20 and CCL24 (Fig. 3). In mild persistent asthmatics, viral infection was associated with increased protein abundance of CXCL10, sICAM-1, CCL2, CCL4, CCL5, CCL20 and CCL24. Virus-positive samples from subjects with mild intermittent asthma showed no significant increases in protein expression.

\section{Associations of nasal lavage biomarker, viral infection and lung function}

Next, we evaluated the strength of association between respiratory tract inflammatory responses and pulmonary function using GEE, including an interaction term between viral presence and inflammatory marker. Most unexpectedly, we found frequent and strong interactions between biomarkers and virus on lung function. For FVC, statistically significant interactions between viral infection and inflammation were seen for CXCL10 mRNA, TLR3 mRNA, IL-4, IL-13, CCL5, CCL20 and CCL24 (Additional file 1: Table S5). The interaction between viral infection and CCL4 approached statistical significance. In contrast, CXCL10 protein showed a negative association with FVC independently of infection.
Figure 4 shows the graphical relationships between nasal lavage biomarker levels and FVC in the absence and presence of viral infection. (Panels for the binary variables TLR3 and IFN- $\lambda$ mRNA are not shown.) In the absence of virus, there were significant negative associations between biomarker and FVC for CXCL10 mRNA, MDA5 mRNA, CXCL10, IL-4, IL-13, CCL4, CCL5, CCL20 and CCL24. In the presence of virus, there were significant positive associations between biomarker and FVC for IL-4, IL-13, CCL5, CCL20 and CCL24.

Longitudinal analysis also showed a significant influence of viral infection on the associations between biomarkers and $\mathrm{FEV}_{1}$ (Additional file 1: Table S6). For $\mathrm{FEV}_{1}$, statistically significant interactions between viral infection and inflammation were seen for CXCL10 and TLR3 mRNA, IL-4 and CCL24 levels. Interactions with CCL4 and CCL5 approached statistsical significance. CXCL10 protein levels had negative associations with $\mathrm{FEV}_{1}$, independent of viral infection. Again, these patterns are discerned graphically (Fig. 5). In the absence of virus, there were significant negative associations between biomarker and $\mathrm{FEV}_{1}$ for CXCL10, RIG-I and MDA5 mRNA. In the presence of virus, there were significant positive associations between biomarker and $\mathrm{FEV}_{1}$ for MDA5 mRNA, IL-4, IL-13, sICAM-1, CCL2, CCL5, CCL20 and CCL24.

The influence of viral infection on the relationships between nasal lavage biomarkers and $\mathrm{FEV}_{1} / \mathrm{FVC}, \mathrm{FEF}_{25}$ 75 and PEF are fully described in this article's Online Repository (Additional file 1: Tables S7-S9). For these lung function parameters there was less of an effect of viral infection on cytokine level. For $\mathrm{FEV}_{1} / \mathrm{FVC}, \mathrm{FEF}_{25-75}$ and 

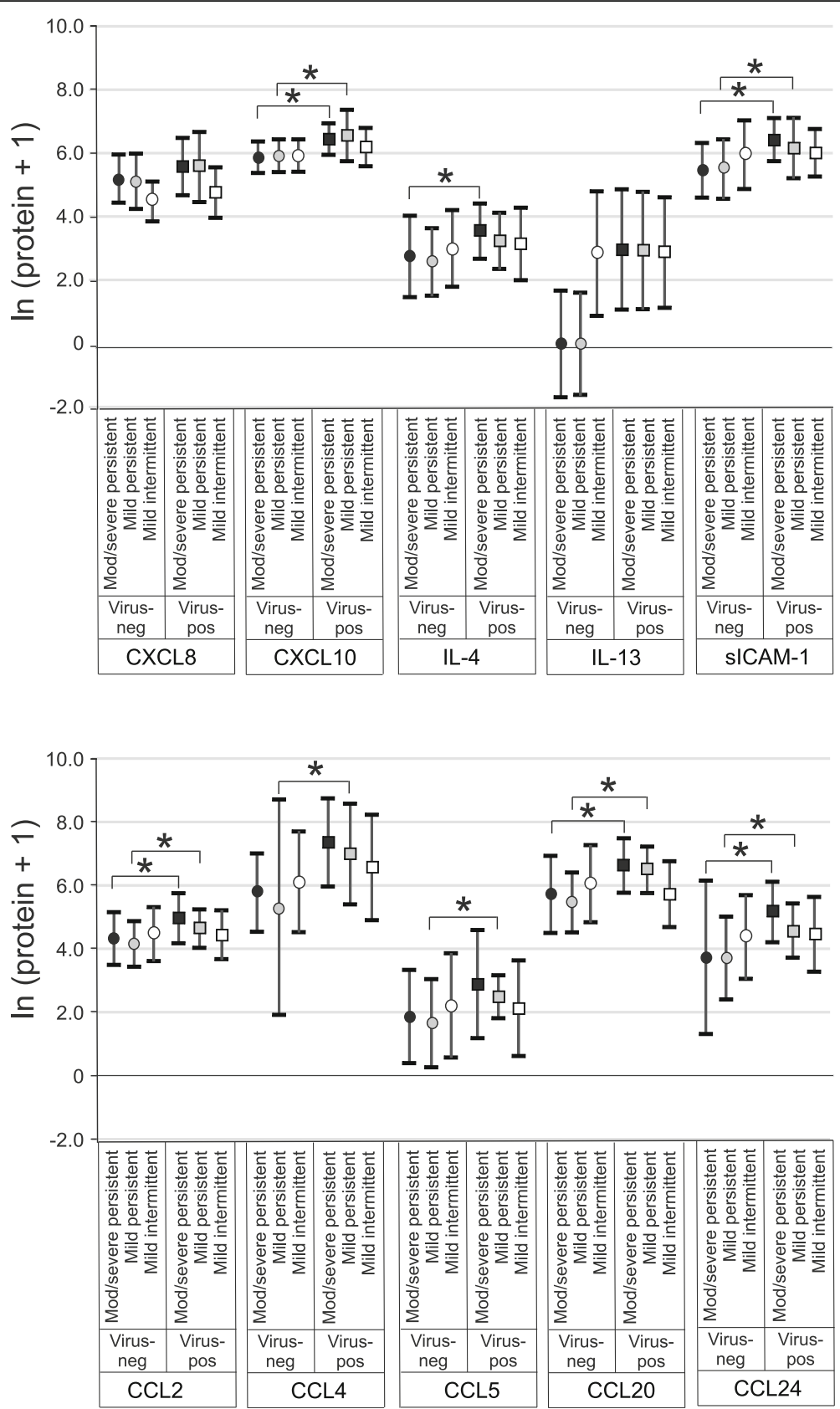

Fig. 3 Effects of viral infection on nasal lavage cytokine concentrations by asthma severity (median \pm IQR). Cytokines were measured by multiplex immune assay. Pairwise comparisons of medians were performed using the Wilcoxon Rank-Sum Test (black symbols, moderate-to-severe persistent asthma; grey symbols, mild persistent asthma; white symbols, mild intermittent asthma; ${ }^{*} p<0.05$ )

PEF, statistically significant interactions between viral infection and inflammation were seen for CXCL10 mRNA. For PEF, interactions between viral infection and RIG-I and TLR3 mRNA were also seen. RIG-I mRNA had a negative association with $\mathrm{FEV}_{1} / \mathrm{FVC}$ independent of viral infection. CXCL8 mRNA and protein levels had a negative association with $\mathrm{FEF}_{25-75}$ independent of viral infection. RIG-I and MDA5 mRNA had negative associations with PEF independent of viral infection. Finally, viral infection was strongly associated with significant reductions in $\mathrm{FEF}_{25-75}$.

\section{Discussion}

Previous studies have shown increased abundance of airway cytokines following both natural $[8-12,19,20]$ and experimental $[21,22]$ colds. In this report, we examine the interactive effects of viral infection and airway cytokines on lung function in patients with 










asthma. We anticipated that, in the absence of virus, children with greater airway inflammation would demonstrate worse airway function. Consistent with this, in the absence of viral infection, several nasal lavage biomarkers correlated negatively with lung function. For example, CXCL10 mRNA, MDA5 mRNA, CXCL10, IL-4, IL-13, CCL4, CCL5, CCL20 and CCL24 were each negatively associated with FVC. We also expected that viral infections would increase inflammation and negatively impact airway function. Accordingly, we found that viral infection had independent positive associations with nearly all nasal lavage biomarkers and, in subjects with moderate-to-severe persistent asthma, negative influences on FVC and $\mathrm{FEV}_{1}$. However, we found many cases in which there was a significant interactive effect between viral infection and lung function, in that the simultaneous presence of viral infection and high cytokine levels was associated with less severe reductions in lung function. Among other associations, in the presence of a virus, IL-4, IL-13, CCL5, CCL20 and CCL24 each positively correlated with both FVC and $\mathrm{FEV}_{1}$. Thus, whereas airway inflammation is associated with reduced lung function in the absence of viral infection, cytokine expression is associated with a diminution of lung function deficits caused by viral infection.

Cytokines promote proliferation and chemotaxis of phagocytes and granulocytes expressing antiviral substances including granule proteins, antimicrobial peptides, proteolytic enzymes and reactive oxygen species, consistent with a protective function. On the other hand, an exuberant response to $\mathrm{RV}$, a virus that infects relatively few airway cells $[23,24]$ and possesses minimal cytotoxic effects compared to influenza or adenovirus [25], could be maladaptive. In a mouse model of RV infection, CXCR2 [26] and TLR2 [27] null mice both show reduced airway inflammation and responsiveness but no change in viral load, suggesting that cytokines mediate RV-induced tissue injury. However, in the present study, we show that, in the context of respiratory viral infection, higher expression of pro-inflammatory cytokines is associated with less severe reductions in lung function. This study may have ramifications for the treatment of viral-induced asthma exacerbations. For example, treatments aimed at reducing the expression of specific pro-inflammatory cytokines may reduce symptoms but also attenuate the potential protective effects of these cytokines on lung function. Indeed, a recent multicenter study of children admitted to the emergency department for asthma exacerabtions showed that viral detection was associated with failure of management with oral corticosteroids and inhaled bronchodilators [28].

As noted above, we also obtained important information regarding the influence of airway cytokines on lung function in the absence of viral infection. IL-4, IL-13 and other type 2 cytokines have long been known to be drivers of allergic asthma [29, 30], and many studies have shown increased chemokine levels in the airways of patients with asthma compared to controls [31-39]. In our longitudinal study, we found that, in the absence of viral infection, CXCL10, IL-4, IL-13, CCL4, CCL5, CCL20 and CCL24 were each negatively associated with FVC. We also found that CXCL10 mRNA MDA5 mRNA and IFN- $\lambda 1$ mRNA were each negatively associated with FVC and $\mathrm{FEV}_{1}$. mRNA expression of CXCL10 and MDA5 are each known to be induced by IFN- $\gamma$, a type 1 cytokine $[40,41]$. While we did not measure IFN- $\gamma$, these data suggest a potential negative influence of this cytokine on lung function in urban children with chronic asthma in the uninfected state. Levels of bronchoalveolar IFN- $\gamma$, a canonical type 1 cytokine, were recently associated with severe asthma [42]. Exhaled breath IFN- $\gamma$ was noted to be a significant indicator of childhood asthma severity, as measured by $\mathrm{FEV}_{1}$ [43].

We were initially surprised that airway cytokines correlated with FVC more strongly than pulmonary function parameters. However, FVC has previously been noted to negatively correlate with outdoor and indoor environmental exposures in children [44-47] and adults [48]. FVC in children has also been negatively correlated with various biomarkers including airway macrophage carbon content [45], exhaled breath malondialdehyde [46] and sputum dipalmitoylphosphatidylcholine [49].

We also obtained new information on the influence of asthma severity on the response to viral infection. Virus-induced induction of airway cytokines was not decreased in children with moderate-to-severe persistent asthma compared to subjects less severe disease, and in many cases viral-induced increases in cytokine level were significant in subjects with persistent asthma but not subjects with intermittent asthma. While there were significant overlapping ranges between the asthma severity groups, these data, obtained from asthmatic subjects experiencing natural colds, do not support the concept that patients with severe asthma have deficient antiviral responses [50-52]. On the other hand, our data are consistent with a recent study showing that, following experimental RV infection, subjects with allergic asthma show greater levels of nasal and bronchial cytokines, chemokines and IFNs compared to control subjects [53]. In addition, the absence of a reduction in viral-induced mRNA or protein expression in children with moderateto-severe persistent asthma demonstrates that the positive associations we found between nasal lavage cytokine level and lung function are not due to increased cytokine production in subjects with better lung function.

There are several limitations to our study. First, we used nasal lavage to sample the respiratory tract of children with asthma. This method allowed repeated collection of samples from children as young as 5 years-old in a relatively 
non-invasive manner. While previous studies have shown that gene expression among asthmatic children is altered similarly in nasal and bronchial airways [53, 54], measurements of nasal lavage cannot actually represent the airway biology, and we did not validate our method by comparing our results with lower respiratory tract specimens such as sputum, breath condensate or bronchoalveolar lavage. Second, we studied a relatively small number of children $(n=53)$. Third, we found that $26.1 \%$ of surveillance samples were positive for virus, compared to $33.7 \%$ of self-reported respiratory illnesses. Thus, subjects were only slightly more likely to have a virus during self-reported sick periods than during surveillance sample collection. We believe the low viral detection rate during symptomatic episodes can be explained by the fact that samples from symptomatic illnesses were not collected in the fall and instead were only collected from January to August, when rhinovirus infections are less prevalent. Cold-like illnesses were unlikely to represent false-negative viral infections, as they were unaccompanied by increases in nasal aspirate MDA5, a doublestranded RNA pattern recognition receptor which was increased in virus-positive samples and has been shown to be induced following RV infection [55]. Nor were cold-like illnesses associated with reduced pulmonary function. Also, the symptom threshold for "sick" sample collection was quite low ( 2 or more). The reasoning behind this was to increase the likelihood of capturing viral illnesses for study. We also offered a $\$ 50$ financial reimbursement for each sick period assessment which served to offset the family time and effort needed to participate in sick assessment/nasal secretion collection. These design elements contributed to a low viral detection rate. For example, a symptom score of two could be achieved simply with a runny and stuffy nose, which could easily represent allergic rhinitis rather than a cold. Fourth, despite extensive training and coaching in spirometry, many expiratory maneuvers were excluded due to inadequate data quality. We have evaluated the impact of our data cleaning procedures and found no systematic exclusion of children compared to the overall study population, and thus feel these procedures are unlikely to introduce selection bias. Fifth, the current analysis evaluates associations between biomarker levels, viral detection, and spirometry obtained on the same day, and does not evaluate for the possibility of lagged effects. Sixth, some of our assessments, such as medication use, asthma severity, and atopy, were based on self-report and were not independently validated, leaving open the possibility of measurement error. Seventh, our data from urban children with asthma may not be generalizable to other groups of asthmatic children. As we have shown previously [14], these children tend to be undertreated, as reflected by the number of subjects who were not taking medication (and therefore labeled as "intermittent asthmatics"). Urban children with asthma who are not treated with inhaled steroids may be more susceptible to viral-induced reductions in airway function than suburban children [56, 57]. Eighth, we did not take into account bacterial colonization in our study. Bacterial colonization could alter the response to rhinovirus infection [58].

Finally, while we found that proximity to high-traffic highways was not a significant predictor of lung function or the relationship between viral exposure and lung function, we have not yet formally examined the effect of specific exposures. Detroit has a history of elevated air pollution and nonattainment of the ozone and particulate matter standards [59]. We previously examined relationships between lung function and ambient levels of ozone and particulate matter in a longitudinal cohort study of school-age children with asthma in Detroit [7]. In a two-pollutant model including $\mathrm{PM}_{10}$ and $\mathrm{O}_{3}$, there was an association between $\mathrm{O}_{3}$ exposure and diurnal variation of $\mathrm{FEV}_{1} 1$ day after exposure in children without self-reported cold symptoms and a larger odds ratio for children with cold symptoms. It is therefore conceivable that specific pollutants could have intensified the effects of viral infection on lung function.

\section{Conclusions}

We conclude that in urban children with asthma, in the absence of respiratory virus, selected nasal lavage cytokines are significantly associated with reduced lung function. These data firmly establish the link between airway inflammation and asthma severity in a longitudinal cohort of children with stable asthma. However, in the presence of viral infection, there is a reversal in the relationship between nasal cytokines and clinical outcome, with higher levels correlating with less severe reductions in lung function. While nasal samples may not reflect lower airway responses, these data suggest that some aspects of the inflammatory response may be protective against viral infection. This study provides new insight into the host response to respiratory viral infections, and may have ramifications for the treatment of viral-induced asthma exacerbations.

\section{Additional files}

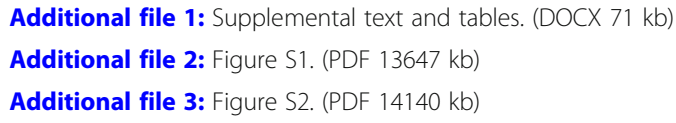

Additional file 1: Supplemental text and tables. (DOCX $71 \mathrm{~kb}$ )

Additional file 2: Figure S1. (PDF $13647 \mathrm{~kb}$ )

Additional file 3: Figure S2. (PDF $14140 \mathrm{~kb}$ )

\section{Acknowledgements}

Community Action Against Asthma (CAAA) is a community-based participatory research partnership that consists of the following organizations: Arab American Center for Community and Social Services, Community Health and Social Services Center Inc., Detroit Hispanic Development Corporation, Detroiters Working for Environmental Justice, Eastside Community Network, Friends of 
Parkside, Southwest Detroit Environmental Vision, and faculty from the University of Michigan School of Medicine and the School of Public Health and a community asthma activist. CAAA is an affiliated partnership of the Detroit Community-Academic Urban Research Center. The authors thank Henry Ford Health System Epidemiology Lab for their collaboration, including initial processing and storage of nasal lavage samples, Ricardo de Majo for database design and technical assistance with encrypted data transfer, and Lucas Carlton for quality assessment of spirometry.

\section{Funding}

This work was supported by National Institutes of Health grants ES016769 (TCL), ES014677 (TGR), HL081420 (MBH) and Al1 14220 (TCL and MBH), and Environmental Protection Agency grant EPA-G2008-STAR-B1 (SAB).

\section{Availability of data and materials}

Not applicable.

\section{Authors' contributions}

$\mathrm{TCL}$ and $\mathrm{MBH}$ conceived and designed the study, analyzed and interpreted data, and drafted and revised the manuscript for important intellectual content. EEM analyzed samples and interpreted data. GBM developed the statistical strategy and analyzed data. XR and KEW analyzed and interpreted the data. ARC and BNE obtained informed consent and collected samples. AMG, ATC, JMR, SRB, GLW and KBO analyzed samples. BM developed the statistical strategy. TGR and SAB designed the study. All authors read and approved the final manuscript.

\section{Ethics approval and consent to participate}

Research was performed in accordance with the Declaration of Helsinki (http://www.wma.net). Informed consent was obtained from parents or legal guardians. This study was approved by the University of Michigan Medical School Institutional Review Board (IRBMED) (ID\# HUM00018442) and conducted according to CBPR principles under the auspices of the CAAA Steering Committee.

\section{Consent for publication}

Not applicable.

\section{Competing interests}

The authors declare that they have no competing interests.

\section{Publisher's Note}

Springer Nature remains neutral with regard to jurisdictional claims in published maps and institutional affiliations.

\section{Author details}

'Departments of Pediatrics and Communicable Diseases, University of Michigan Medical School, 1150 W. Medical Center Dr., Building MSRB2, Room 3570B, Ann Arbor, MI 48109-5688, USA. ${ }^{2}$ Molecular and Integrative Physiology, University of Michigan Medical School, Ann Arbor, USA. ${ }^{3}$ Departments of Biostatistics, University of Michigan School of Public Health, University of Michigan, Ann Arbor, Ml 48109, USA. ${ }^{4}$ Environmental Health Sciences, University of Michigan School of Public Health, University of Michigan, Ann Arbor, MI 48109, USA. ${ }^{5}$ Epidemiology, University of Michigan School of Public Health, University of Michigan, Ann Arbor, Ml 48109, USA. ${ }^{6}$ Health Behavior/Health Education, University of Michigan School of Public Health, University of Michigan, Ann Arbor, Ml 48109, USA.

Received: 17 May 2018 Accepted: 24 October 2018 Published online: 21 November 2018

\section{References}

1. Carr W, Zeitel L, Weiss K. Variations in asthma hospitalizations and deaths in New York City. Am J Public Health. 1992;82:59-65.

2. Gottlieb DJ, Beiser AS, O'Connor GT. Poverty, race, and medication use are correlates of asthma hospitalization rates. A small area analysis in Boston. Chest. 1995;108:28-35.

3. Akinbami L, Moorman JE, Liu X. Asthma prevalence, health care use, and mortality: United States, 2005-2009. Natl Health Stat Report. 2011;12:1-14.

4. Rosenstreich DL, Eggleston $P$, Kattan M, Baker D, Slavin RG, Gergen P, Mitchell H, McNiff-Mortimer K, Lynn H, Ownby D, Malveaux F. The role of cockroach allergy and exposure to cockroach allergen in causing morbidity among inner-city children with asthma. N Engl J Med. 1997;336:1356-63.

5. Eggleston PA, Malveaux FJ, Butz AM, Huss K, Thompson L, Kolodner K, Rand CS. Medications used by children with asthma living in the inner city. Pediatrics. 1998;101:349-54.

6. Gergen PJ, Mitchell H, Lynn H. Understanding the seasonal pattern of childhood asthma: results from the national cooperative inner-city asthma study (NCICAS). J Pediatr. 2002;141:631-6.

7. Lewis TC, Robins TG, Dvonch JT, Keeler GJ, Yip FY, Mentz GB, Lin X, Parker EA, Israel BA, Gonzalez L, Hill Y. Air pollution-associated changes in lung function among asthmatic children in Detroit. Environ Health Perspect. 2005;113:1068-75.

8. Lewis TC, Henderson TA, Carpenter AR, Ramirez IA, McHenry CL, Goldsmith AM, Ren X, Mentz GB, Mukherjee B, Robins TG, Joiner TA, Mohammad LS, Nguyen ER, Burns MA, Burke DT, Hershenson MB. Nasal cytokine responses to natural colds in asthmatic children. Clin Exp Allergy. 2012;42:1734-44.

9. Pizzichini MM, Pizzichini E, Efthimiadis A, Chauhan AJ, Johnston SL, Hussack P, Mahony J, Dolovich J, Hargreave FE. Asthma and natural colds. Inflammatory indices in induced sputum: a feasibility study. Am J Respir Crit Care Med. 1998;158:1178-84.

10. Teran LM, Seminario MC, Shute JK, Papi A, Compton SJ, Low JL, Gleich GJ, Johnston SL. RANTES, macrophage-inhibitory protein 1a, and the eosinophil product major basic protein are released into upper respiratory secretions during virus-induced asthma exacerbations in children. J Infect Dis. 1999;179:677-81.

11. Grissell TV, Powell H, Shafren DR, Boyle MJ, Hensley MJ, Jones PD, Whitehead BF, Gibson PG. IL-10 gene expression in acute virus-induced asthma. Am J Respir Crit Care Med. 2005;172:433-9.

12. Santiago J, Hernandez-Cruz JL, Manjarrez-Zavala ME, Montes-Vizuet R, Rosete-Olvera DP, Tapia-Diaz AM, Zepeda-Peney H, Teran LM. Role of monocyte chemotactic protein-3 and -4 in children with virus exacerbation of asthma. Eur Respir J. 2008;32:1243-942.

13. Vette A, Burke J, Norris G, Landis M, Batterman S, Breen M, Isakov V, Lewis T, Gilmour MI, Kamal A, Hammond D, Vedantham R, Bereznicki S, Tian N, Croghan C. The near-road exposures and effects of urban air pollutants study (NEXUS): study design and methods. Science Total Environ. 2013;448:38-47.

14. Lewis T, Robins T, Joseph C, Parker E, Israel B, Rowe Z, Edgren K, Salinas M, Martinez M, Brown R. Identification of gaps in the diagnosis and treatment of childhood asthma using a community-based participatory research approach. J Urban Health. 2004;81:472-88.

15. Lemanske RF, Jackson DJ, Gangnon RE, Evans MD, Li Z, Shult PA, Kirk CJ, Reisdorf E, Roberg KA, Anderson EL, Carlson-Dakes KT, Adler KJ, Gilbertson-White S, Pappas TE, Dasilva DF, Tisler CJ, Gern JE. Rhinovirus illnesses during infancy predict subsequent childhood wheezing. J Allergy Clin Immunol. 2005;116:571-7.

16. Liang K-Y, Zeger SL. Longitudinal data analysis using generalized linear models. Biometrika. 1986;73:13-22.

17. Ballinger GA. Using generalized estimating equations for longitudinal data analysis. Organ Res Methods. 2004;7:127-50.

18. Ma Y, Mazumdar M, Memtsoudis SG. Beyond repeated-measures analysis of variance: advanced statistical methods for the analysis of longitudinal data in anesthesia research. Reg Anesth Pain Med. 2012;37:99-105.

19. Miller EK, Hernandez JZ, Wimmenauer V, Shepherd BE, Hijano D, Libster R, Serra ME, Bhat N, Batalle JP, Mohamed Y, Reynaldi A, Rodriguez A, Otello M, Pisapia N, Bugna J, Bellabarba M, Kraft D, Coviello S, Ferolla FM, Chen A, London SJ, Siberry GK, Williams JV, Polack FP. A mechanistic role for type III IFN- $\lambda 1$ in asthma exacerbations mediated by human rhinoviruses. Am J Respir Crit Care Med. 2012;185:508-16.

20. Manthei DM, Schwantes EA, Mathur SK, Guadarrama AG, Kelly EA, Gern JE, Jarjour NN, Denlinger LC. Nasal lavage VEGF and TNF-a levels during a natural cold predict asthma exacerbations. Clin Exp Allergy. 2014;44:1484-93.

21. Message SD, Laza-Stanca V, Mallia P, Parker HL, Zhu J, Kebadze T, Contoli M, Sanderson G, Kon OM, Papi A, Jeffery PK, Stanciu LA, Johnston SL. Rhinovirus-induced lower respiratory illness is increased in asthma and related to virus load and Th1/2 cytokine and IL-10 production. Proc Natl Acad Sci U S A. 2008;105:13562-7.

22. Adura PT, Reed E, Macintyre J, del Rosario A, Roberts J, Pestridge R, Beegan R, Boxall CB, Xiao C, Kebadze T, Aniscenko J, Cornelius V, Gern JE, Monk PD, Johnston SL, Djukanović R. Experimental rhinovirus 16 infection in moderate asthmatics on inhaled corticosteroids. Eur Respir J. 2014;43:1186-9.

23. Arruda E, Boyle TR, Winther B, Pevear DC, Gwaltney JM, Hayden FG. Localization of human rhinovirus replication in the upper respiratory tract by in situ hybridization. J Infect Dis. 1995;171:1329-33. 
24. Mosser AG, Brockman-Schneider R, Amineva S, Burchell L, Sedgwick JB, Busse WW, Gern JE. Similar frequency of rhinovirus-infectible cells in upper and lower airway epithelium. J Infect Dis. 2002;185:734-43.

25. Winther B, Gwaltney JM, Hendley JO. Respiratory virus infection of monolayer cultures of human nasal epithelial cells. Am Rev Respir Dis. 1990;141:839-45.

26. Nagarkar DR, Wang Q, Shim J, Zhao Y, Tsai WC, Lukacs NW, Sajjan U, Hershenson MB. CXCR2 is required for neutrophilic airway inflammation and hyperresponsiveness in a mouse model of human rhinovirus infection. J Immunol. 2009;183:6698-707.

27. Han M, Chung Y, Young Hong J, Rajput C, Lei J, Hinde JL, Chen Q, Weng SP, Bentley JK, Hershenson MB. Toll-like receptor 2-expressing macrophages are required and sufficient for rhinovirus-induced airway inflammation. J Allergy Clin Immunol. 2016;138:1619-30.

28. Ducharme FM, Zemek R, Chauhan BF, Gravel J, Chalut D, Poonai N, Guertin MC, Quach C, Blondeau L, Laberge S, Network. DrgotPERiCP: factors associated with failure of emergency department management in children with acute moderate or severe asthma: a prospective, multicentre, cohort study. Lancet Respir Med. 2016;4:990-8.

29. Robinson DS, Hamid Q, Ying S, Tsicopoulos A, Barkans J, Bentley AM, Corrigan C, Durham SR, Kay AB. Predominant TH2-like bronchoalveolar Tlymphocyte population in atopic asthma. N Engl J Med. 1992;326:298-304.

30. Woodruff PG, Modrek B, Choy DF, Jia G, Abbas AR, Ellwanger A, Arron JR, Koth LL, Fahy JV. T-helper type 2-driven inflammation defines major subphenotypes of asthma. Am J Respir Crit Care Med. 2009;180:388-95.

31. Alam R, York J, Boyars M, Stafford S, Grant JA, Lee J, Forsythe P, Sim T, Ida N. Increased MCP-1, RANTES, and MIP-1alpha in bronchoalveolar lavage fluid of allergic asthmatic patients. Am J Respir Crit Care Med. 1996;153:1398-404.

32. Holgate ST, Bodey KS, Janezic A, Frew AJ, Kaplan AP, Teran LM. Release of RANTES, MIP-1a, and MCP-1 into asthmatic airways following endobronchial allergen challenge. Am J Respir Crit Care Med2. 1997;156: 1377-83.

33. Tillie-Leblond I, Hammad H, Desurmont S, Pugin J, Wallaert B, Tonnel A-B, Gosset P. CC chemokines and interleukin-5 in bronchial lavage fluid from patients with status asthmaticus. Am J Respir Crit Care Med. 2000;162:586-92.

34. Ravensberg AJ, Ricciardolo FLM, van Schadewijk A, Rabe KF, Sterk PJ, Hiemstra PS, Mauad T. Eotaxin-2 and eotaxin-3 expression is associated with persistent eosinophilic bronchial inflammation in patients with asthma after allergen challenge. J Allergy Clin Immunol. 2005;115:779-85.

35. Dent G, Hadjicharalambous C, Yoshikawa T, Handy RLC, Powell J, Anderson IK, Louis R, Davies DE, Djukanovic R. Contribution of eotaxin-1 to eosinophil chemotactic activity of moderate and severe asthmatic sputum. Am J Respir Crit Care Med. 2004;169:1110-7

36. Ko FWS, Lau CYK, Leung TF, Wong GWK, Lam CWK, Lai CKW, Hui DSC. Exhaled breath condensate levels of eotaxin and macrophage-derived chemokine in stable adult asthma patients. Clin Exp Allergy. 2006;36:44-51.

37. Fitzpatrick AM, Higgins M, Holguin F, Brown LAS, Teague WG. The molecular phenotype of severe asthma in children. J Allergy Clin Immunol. 2010;125:851-7 e818.

38. Hastie AT, Moore WC, Meyers DA, Vestal PL, Li H, Peters SP, Bleecker ER. Analyses of asthma severity phenotypes and inflammatory proteins in subjects stratified by sputum granulocytes. J Allergy Clin Immunol. 2010;125: 1028-36 e1013.

39. Robroeks CMHHT, Rijkers GT, Jöbsis Q, Hendriks HJE, Damoiseaux JGMC, Zimmermann LI, Van Schayck OP, Dompeling E. Increased cytokines, chemokines and soluble adhesion molecules in exhaled breath condensate of asthmatic children. Clin Exp Allergy. 2010;40:77-84.

40. Narumi S, Hamilton TA. Inducible expression of murine IP-10 mRNA varies with the state of macrophage inflammatory activity. J Immunol. 1991;146:3038-44.

41. Kang DC, Gopalkrishnan RV, Wu Q, Jankowsky E, Pyle AM, Fisher PB. mda-5: an interferon-inducible putative RNA helicase with double-stranded RNAdependent ATPase activity and melanoma growth-suppressive properties. Proc Natl Acad Sci U S A. 2002;99:637-42.

42. Raundhal M, Morse C, Khare A, Oriss TB, Milosevic J, Trudeau J, Huff R, Pilewski J, Holguin F, Kolls J, Wenzel S, Ray P, Ray A. High IFN- $\gamma$ and low SLPI mark severe asthma in mice and humans. J Clin Invest. 2015;125:3037-50.

43. Robroeks CMHHT, Van De Kant KDG, Jöbsis Q, Hendriks HJE, Van Gent R, Wouters EFM, Damoiseaux JGMC, Bast A, Wodzig WKWH, Dompeling E. Exhaled nitric oxide and biomarkers in exhaled breath condensate indicate the presence, severity and control of childhood asthma. Clin Exp Allergy. 2007;37:1303-11.
44. Koenig JQ, Mar TF, Allen RW, Jansen K, Lumley T, Sullivan JH, Trenga CA, Larson T, Liu $\sqcup$. Pulmonary effects of indoor- and outdoor-generated particles in children with asthma. Environ Health Perspect. 2005;113:499-503.

45. Kulkarni N, Pierse N, Rushton L, Grigg J. Carbon in airway macrophages and lung function in children. N Engl J Med. 2006;355:21-30.

46. Romieu I, Barraza-Villarreal A, Escamilla-Nuñez C, Almstrand A-C, DiazSanchez D, Sly PD, Olin A-C. Exhaled breath malondialdehyde as a marker of effect of exposure to air pollution in children with asthma. J Allergy Clin Immunol. 2008;121:903-9 e906.

47. Barone-Adesi F, Dent JE, Dajnak D, Beevers S, Anderson HR, Kelly FJ, Cook DG, Whincup PH. Long-term exposure to primary traffic pollutants and lung function in children: cross-sectional study and meta-analysis. PLoS One. 2015;10:e0142565.

48. Kunzli N, Ackermann-Liebrich U, Brandli O, Tschopp J, Schindler C, Leuenberger P. Clinically "small" effects of air pollution on FVC have a large public health impact. Swiss study on air pollution and lung disease in adults (SAPALDIA) - team. Eur Respir J. 2000;15:131-6.

49. Shaheen MA, Mahmoud MA, Abdel Aziz MM, El Morsy HI, Abdel Khalik KA. Sputum dipalmitoylphosphatidylcholine level as a novel airway inflammatory marker in asthmatic children. Clin Respir J. 2009;3:95-101.

50. Wark PA, Johnston SL, Bucchieri F, Powell R, Puddicombe S, Laza-Stanca $\checkmark$, Holgate ST, Davies DE. Asthmatic bronchial epithelial cells have a deficient innate immune response to infection with rhinovirus. J Exp Med. 2005;201:937-47.

51. Contoli M, Message SD, Laza-Stanca V, Edwards MR, Wark PA, Bartlett NW, Kebadze T, Mallia P, Stanciu LA, Parker HL, Slater L, Lewis-Antes A, Kon OM, Holgate ST, Davies DE, Kotenko SV, Papi A, Johnston SL. Role of deficient type III interferon-lambda production in asthma exacerbations. Nat Med. 2006;12:1023-6.

52. Sykes A, Macintyre J, Edwards MR, del Rosario A, Haas J, Gielen V, Kon OM, McHale M, Johnston SL. Rhinovirus-induced interferon production is not deficient in well controlled asthma. Thorax. 2014;69:240-6.

53. Hansel TT, Tunstall T, Trujillo-Torralbo M-B, Shamji B, del-Rosario A, Dhariwal J, Kirk PDW, Stumpf MPH, Koopmann J, Telcian A, Aniscenko J, Gogsadze L, Bakhsoliani E, Stanciu L, Bartlett N, Edwards M, Walton R, Mallia P, Hunt TM, Hunt TL, Hunt DG, Westwick J, Edwards M, Kon OM, Jackson DJ, Johnston SL. A comprehensive evaluation of nasal and bronchial cytokines and chemokines following experimental rhinovirus infection in allergic asthma: increased interferons (IFN- $\gamma$ and IFN- $\lambda$ ) and type 2 inflammation (IL-5 and IL13). EBioMed. 2017;19:128-38.

54. Poole A, Urbanek C, Eng C, Schageman J, Jacobson S, O'Connor BP, Galanter JM, Gignoux CR, Roth LA, Kumar R, Lutz S, Liu AH, Fingerlin TE, Setterquist RA, Burchard EG, Rodriguez-Santana J, Seibold MA. Dissecting childhood asthma with nasal transcriptomics distinguishes subphenotypes of disease. J Allergy Clin Immunol. 2014;133:670-8 e612.

55. Wang Q, Nagarkar DR, Bowman ER, Schneider D, Gosangi B, Lei J, Zhao Y, McHenry CL, Burgens RV, Miller DJ, Sajjan U, Hershenson MB. Role of double-stranded rna pattern recognition receptors in rhinovirus-induced airway epithelial cell responses. J Immunol. 2009; 183:6989-97.

56. Liu L, Poon R, Chen L, Frescura A-M, Montuschi P, Ciabattoni G, Wheeler A, Dales R. Acute effects of air pollution on pulmonary function, airway inflammation, and oxidative stress in asthmatic children. Environ Health Perspect. 2009;117:668-74.

57. Delfino RJ, Zeiger RS, Seltzer JM, Street DH, McLaren CE. Association of asthma symptoms with peak particulate air pollution and effect modification by antiinflammatory medication use. Environ Health Perspect. 2002;110:A607-17.

58. Kloepfer KM, Lee WM, Pappas TE, Kang TJ, Vrtis RF, Evans MD, Gangnon RE, Bochkov YA, Jackson DJ, Lemanske RF Jr, Gern JE. Detection of pathogenic bacteria during rhinovirus infection is associated with increased respiratory symptoms and asthma exacerbations. J Allergy Clin Immunol. 2014;133: 1301-7 e1303.

59. Keeler Gerald J, Dvonch T, Yip Fuyuen Y, Parker Edith A, Isreal Barbara A, Marsik Frank J, Morishita M, Barres James A, Robins Thomas G, BrakefieldCaldwell W, Sam M. Assessment of personal and community-level exposures to particulate matter among children with asthma in Detroit, Michigan, as part of community action against asthma (CAAA). Environ Health Perspect. 2002;110:173-81. 